\title{
Møte med det hellige i klinisk praksis
}

\author{
Møter med «det hellige» hører til hverdagserfaringer i medisinen og omsorgsyrker. Vi drøfter her hvordan \\ bevisstheten om dette kan tilbakeføres til vår yrkespraksis. Den sekulære humanismen inneholder selv- \\ motsigelser som sannsynligvis ikke kan mestres med mindre «det hellige» får plass som en motvekt \\ til det ensidig formålsrasjonelle i klinisk og samfunnsmedisinsk praksis.
}

\begin{abstract}
En kvinne i 80-årene var på EMs kontor og fortalte opprørt om hva som hadde hendt henne siden hun var uteblitt fra konsultasjoner. Hun hadde brukket lårhalsen seks måneder tidligere, fått satt inn en hemiprotese og vært til rehabiliteringsopphold ved to ulike institusjoner. Hun var i den forbindelse blitt henvist til MR av hodet og demensutredning ved en sykehuspoliklinikk. Oppsøkende pleie- og omsorgsteam hadde besøkt henne hjemme like før. I konsultasjonen fortalte
\end{abstract} hun: «Jeg har avbestilt utredningen på sykehusavdelingen! Demens! Jeg? Nei, jeg har klart å lære meg programvalgene på den nye vaskemaskinen og den nye flatskjermen, og jeg har ingen grunn til å møte opp til slike undersøkelser. Sykepleierne som var hjemme hos meg var elskverdige nok, men de satt bare og snakket om hva jeg hadde behov for: knotter og oppbygninger både her og der. Doseteforhøyning og håndtak, ny stol med katapult og jeg vet ikke hva. Dagen før var det en mann hjemme hos meg og monterte en alarm på komfyren. Jeg hadde ikke bedt om det. Da de hadde holdt på slik en stund, sa jeg til dem: «Hør her. Dere er nå i mitt hjem, og her er det jeg som bestemmer. Den dagen jeg må krype til korset, skal dere få beskjed, men det er ikke nå. Jeg klarer meg utmerket. Når dere går, kan dere også ta med alarmen på komfyren». EM anerkjente henne med et «Bravo!», men da så hun bare ned og sa stille: «Det er ikke krenkelsen og mitt forsvar som er poenget. På institusjonene som jeg har vært på i det siste har jeg erfart at alle de andre finner seg i slik behandling. Det er ingen som protesterer. Det er det jeg synes er så skremmende.»

\section{«Where angels fear to tread,}

fools rush in.» Dette ordtaket tjener som tittel på en bok der Gregory og Mary Catherine Bateson utvikler en grunnlagsforståelse (epistemologi) for «det hellige», forstått som et nødvendig og komplementært element i alle økologiske systemer (1). Poenget er at all utvikling er avhengig av et skapende og språkløst element som ikke kan kategoriseres i en ideologi eller et trossystem. Det er ingen som har eiendomsrett over dette elementet, og det forsvinner eller perverteres hvis det betvinges.
Historien over illustrerer hvordan terapeuter og omsorgspersoner ensidig stoler på sin prosedyrekunnskap, hvordan de derved gjør epistemologiske feil ved at de forutsetter at slik formålsrasjonell kunnskap er tilstrekkelig, og tråkker over grenser som er hellige $i$ alle menneskers liv.

«Det hellige» assosieres gjerne med trosmessig identitet. Vi forstår begrepet derimot slik at det også kan gjenkjennes av dem som er mer sekulært innstilt. Religionsfilosofen Espen Dahl kaller «det hellige» nettopp for «en svak gest mot en religiøs horisont» (2). Det opprørende i historien over er fra et sekulært ståsted bruddet på integritetens grenser. I vårt perspektiv er det også et hellighetsbrudd ved at det krenker kvinnens mulighet for spontan, «åpenbarende» mestring av hverdagen. Om «det hellige» er glemt, så er imidlertid «helse» nærværende som aldri før.

\section{Den terapeutiske kultur}

Det senmoderne menneskets utbredte opptatthet av fysisk og psykisk velvære kan knyttes til «en terapeutisk vending» der den protestantiske etikken rettet mot etterlivet ble endret til en terapeutisk etikk med fokus på størst mulig fysisk og psykisk velvære her og nå (3). Kort sagt: Helse erstatter frelse. Det historisk nye med den terapeutiske etikken er at Selvet gjøres til den fremste moralske autoriteten (Hva føles rett for meg i mitt liv?) på bekostning av ytre autoriteter som Gud eller Regenten (4). Den nye profesjonen som erstatter prestens tidligere støttefunksjon er psykologene, men også andre helsedisipliner og livsstilseksperter - fra den kosmetiske kirurgen til den personlige treneren - får sin eksistensberettigelse i dette kulturelle klimaet $(5,6)$.

I medisinen er ekvivalenten til denne utviklingen «medikalisering». Helsevesenet tilkjemper seg et stadig økende mandat for å diagnostisere, forebygge og behandle sykdommer. Sykdomsbegrepene blir gjenstand for inflasjon, og en voksende del av befolkningen blir sykeliggjort for tilstander som tidligere var normalvariasjon, blir syke av falskt positive testresultater eller behandlet for pseudosykdom, for eksempel ikkebiologisk kreft $(7,8)$.
En vedvarende bekymring helt siden freudianismens storhetstid i 1950-årene er at den terapeutiske kulturen i realiteten er en kulturell oppskrift for en oppblomstring av psykiske lidelser. Dette fordi dens radikale opphøyelse av selvet, tross historiske utfoldelsesmuligheter, gir en for svak integrering av mennesket i et større meningsfellesskap (9). Det senmoderne samfunn kan ikke gi rom for hellighetserfaringer ved utelukkende å være fundert på en blind tro på medisin og psykologi. Kulturkritikeren Philip Rieff sa at den moderne helbreder ikke lenger har makten til å transformere mennesket, kun informere det om dets valg (10). Mennesket står tilbake ensomt og selvopptatt $(5,11)$.

\section{Et felles problem}

«Humanistisk medisin» etterlyses, med rette (12). Denne etterlysning må forstås som en appell om at humanismen ikke må utvikle seg til hovmod, der man tror at alle problemer kan løses om vi utvikler teknologien godt nok. En ydmyk posisjon i det humanistiske prosjekt er viktig. Samtidig bygger dette perspektivet gjerne på en sekulær idé om at det er menneskets egen erkjennelseskraft som kan ivareta respekt og verdighet $i$ omsorgs- og behandlingsrelasjoner, helt uten å gi innrømmelser til livets hellighetsdimensjon.

Humanismen møter seg selv i døren. Det er nemlig en misforståelse å hevde at naturvitenskapelig medisin og den teknologi den har frembrakt, ikke er en del av det humanistiske prosjekt som renessansen og opplysningstiden skapte (13). Vitenskapen og teknologiens utvikling i det moderne samfunn ville ikke vært mulig uten at kirkens erkjennelsesmonopol ble brutt. Samtidig ble troen og det hellige gjort om til et bekjennelses- og frelsesprosjekt med liten relevans for vår samhørighet med naturen $(14,15)$. På denne måten lå det en kilde til pervertering både for den sekulære humanismens grenseløse konsum og overtro på vitenskapelige løsninger, $o g$ for kristentroens manglende omsorg for det jordiske.

\section{Et felles ansvar}

De troende og de sekulære har en felles utfordring. Det moderne prosjekt var preget 


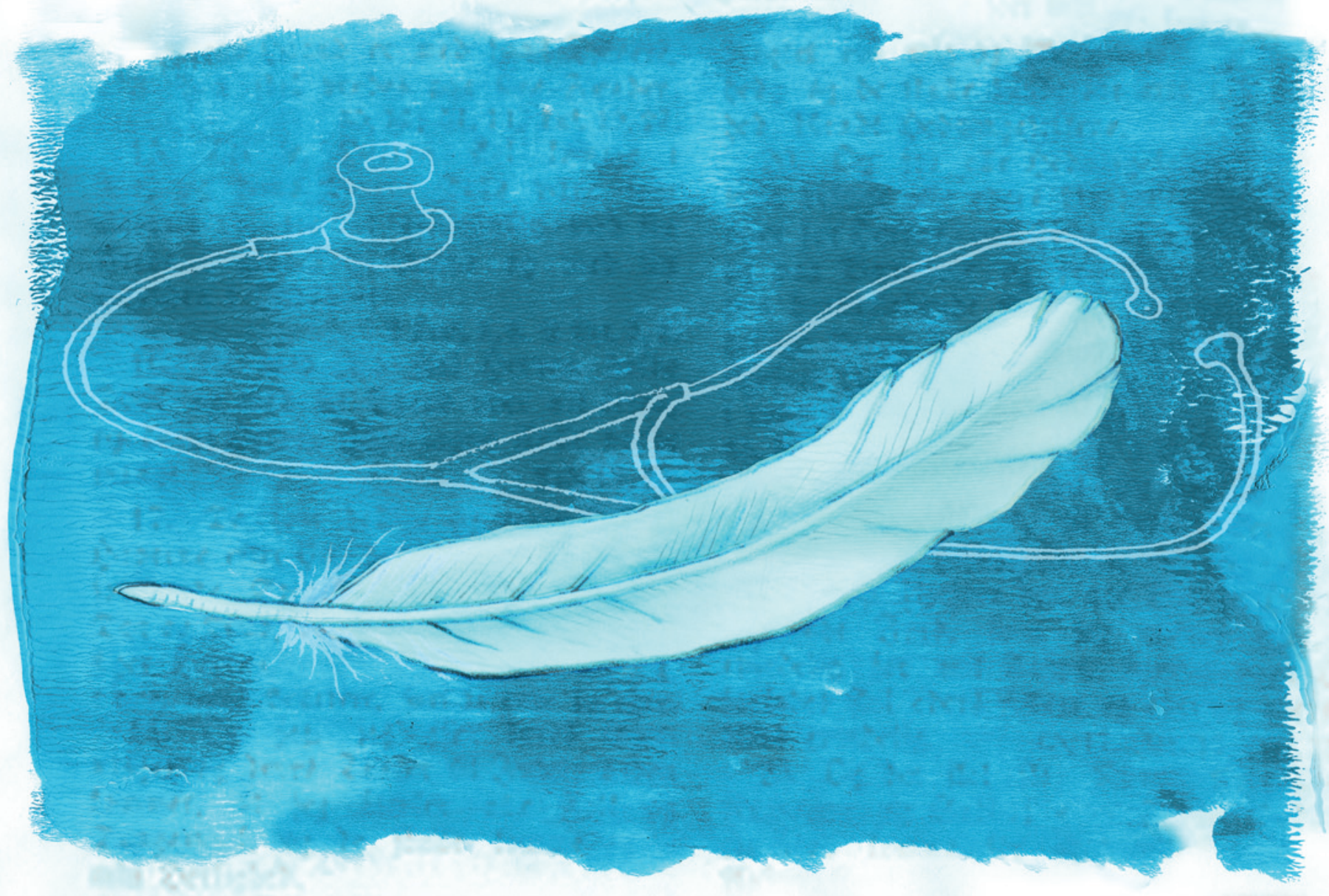

Illustrasjon Stein Løken

av «avfortryllelse», mens det senmoderne preges av «refortryllelse». Tros- og tillitsdimensjonen ved livene våre kan ikke stues bort på mørkeloftet, men må løftes frem $i$ åpne og sårbare dialoger der den sekulære har noe å lære av den troende og omvendt $(11,16)$. De endringene som skjer i teologien og i kristenlivet, med større fokus på skapelsesteologi, har derfor stor betydning. Kristne fremmer et panenteistisk ståsted, der Gud åpenbarer seg i naturen, $\mathrm{i}$ hverdagen og i relasjonene. Vi får en sterkere vektlegging på den første trossetning, på skapelses- og spontanitetsdimensjonen $\mathrm{i}$ livene våre og på den kroppslige tilhørighetsdimensjonen i troen (17-19). Stuart Kauffman «avlyser» det moderne reduksjonistiske prosjekt som vil sette alle fenomen i kosmos på formel. Han hevder at alle livsformer har et element av emergens ved seg. Han foreslår at den sekulære må lære seg å ta ordet «hellig» i sin munn for å ivareta det evig spontane og uforutsigbare i tilværelsen (20).

\section{Det allmennreligiøse i terapien}

Vi forsøker ikke å underslå at medisinen og psykologien utnytter det usikre selvet med tekniske «løsninger» på umettelig døds- og sykdomsangst, men vi observerer at vår samtid også preges av strømninger som illustrerer at det allmennreligiøse allerede er på vei inn i fagene våre. Eksempler er kognitiv terapi, som baserer seg på fenomenologiske kulturstrømninger, buddhistiske bønneritualer som i den sekulære språkdrakt kalles oppmerksomhetstrening (21), og narrativ terapi, der fortellingen har fătt sin renessanse (22).

Vi avslutter med en historie som viser hvordan hellighetsdimensjonen ved terapien kan ivaretas:

EM hadde en student utplassert som deltakende observatør da en sterkt plaget kvinnelig pasient var til konsultasjon. Kvinnen ble spurt om hun kunne fortelle studenten hva som hadde vært betydningsfullt for hennes bedring i mestrings- og funksjonsevne i løpet av det halvannet året hun hadde konsultert fastlegen. «Gud er blitt mer levende for meg.» Hun rakte frem hendene og formet dem som en skål. "Nå hviler jeg $i$ Guds hender på en tryggere måte. Jeg trodde jeg visste hva aksept betydde, men nå har jeg fått en grunnleggende forståelse av hva det betyr å akseptere. Jeg har endatil begynt å finne kilder til energi og livskraft i livet mitt. Ikke misforstå meg.
Han (EM) har aldri pådyttet meg noe som helst. Han har bare spurt meg.» «Du vet jo at jeg ikke tror på en ekstern guddom i tilværelsen. Jeg pleier å kalle meg for kristen indianer og skapbuddhist», brøt EM inn. «Du vet jo at heller ikke jeg tror på en liten Gud,» svarte hun.

\section{Postludium}

Vi fremmer disse synsmåtene med ærbødighet. Vi vil ikke oppfordre til misbruk av behandlingsrelasjoner til å fremme terapeutens livssynspreferanser. Samtidig plages vi av at den allment vedtatte etos i norsk helsevesen ikke ser det problematiske $i$ at tillitsdimensjonen i livene våre blir krenket av teknisk instrumentalisme og utnytting av folks døds- og sykdomsangst. Helsemyndighetene aksepterer stadig at friske mennesker inviteres på forføreriske måter til helseundersøkelser med marginale effekter $(23,24)$.

Hensikten med denne artikkelen har vært å åpne for kliniske, samfunnsmedisinske og politiske dialoger som legitimerer trygghet, tillit og tilhørighet i naturen, i menneskelige relasjoner og i fellesskap i demokratiske samfunn. Vi har kritisert den pietistiske tradisjonen i vår kristne kultur, men noe har 
pietistene rett i: Det er behov for «å vende om før det er for sent».

\section{Eivind Meland}

eivind.meland@isf.uib.no

Institutt for samfunnsmedisinske fag

\section{Ole Jacob Madsen}

Senter for vitenskapsteori

Universitetet i Bergen

Kasuistikkene er gjengitt med pasientenes tillatelse.

Eivind Meland (f. 1950) er spesialist i allmennmedisin, fastlege ved Olsvik legesenter og professor ved Institutt for samfunnsmedisinske fag, Universitetet i Bergen.

Forfatter har fylt ut ICMJE-skjemaet og oppgir ingen interessekonflikter.

Ole Jacob Madsen (f. 1978) Er cand.psychol., cand.philol. i filosofi, ph.d. og gjesteforsker ved Senter for vitenskapsteori. Han tok profesjonsstudiet i psykologi med hovedoppgaven Den terapeutiske etos - en analyse av psykologien i senmoderniteten.

Forfatter har fylt ut ICMJE-skjemaet og oppgir ingen interessekonflikter.

\section{Litteratur}

1. Bateson G, Bateson MC. Angels fear. Towards an epistomology of the sacred. New York, NY: MacMillan, 1987.

2. Dahl E. Det hellige. Perspektiver. Oslo: Universitetsforlaget, 2008

3. Lears TJJ. From salvation to self-realization. Advertising and the therapeutic roots of the consumer culture, 1880-1930. I: Fox RW, Lears TJJ, red. The culture of consumption: critical essays in American history 1880-1980. New York, NY: Pantheon Books, 1983: 1-38.

4. Nolan JL. The therapeutic state: justifying government at century's end. New York, NY: New York University Press, 1998

5. Madsen OJ. Den terapeutiske kultur. Oslo: Univer sitetsforlaget, 2010

6. Abbott A. The System of professions. Chicago, IL: The University of Chicago Press, 1988

7. Fugelli P. O-visjonen. Essays om helse og frihet Oslo: Universitetsforlaget, 2003

8. Brodersen J, Hovelius B, Hvas L. Skapar vården ohälsa? Allmänmedicinska reflektioner. Lund Studentlitteratur, 2009.

9. Illouz E. Saving the modern soul: therapy, emotions, and the culture of self-help. Berkeley, CA: University of California Press, 2008.

10. Rieff P. The triumph of the therapeutic: Uses of faith after Freud (with a new preface). Chicago, IL: University of Chicago Press, 1987.

11. Taylor C. A secular age. Cambridge, MA: Harvard University Press, 2008.

12. Schei E, Gulbrandsen A. Forstår du, doktor? Mot en humanistisk legeutdanning. Oslo: Tano Aschehoug, 2000

13. Wifstad $\AA$. Humanistisk medisin. Tidsskr Nor Lægeforen 2007: 127: 2967-9.

14. Hoffmeyer J. Tro på tvivl. Kritik av religiøs og videnskabelig ufornuft. Charlottenlund: Ries, 2009.
15. Jensen 0 . Historien om K.E. Løgstrup. København: Anis, 2007

16. Habermas J. Religion in the Public Sphere. Eur J Philos 2010; 14: 1-25.

17. Jensen O. Opphav og omgivelse. Løgstrup og naturen. I: Bugge D, Böwadt PR, Sørensen PA, red. Løgstrups mange ansigter. København: Anis, 2005 147-58.

18. Løgstrup KE. Opgør med Kierkegaard. København Nordisk Forlag, 1967.

19. Thelle NR. Kjære Siddhartha! Brev og samtaler i grenseland mellom $\varnothing$ st og vest. Vikersund: Oriens Forlag. 2005

20. Kauffman SA. Reinventing the sacred. A new view of science, reason and religion. New York, NY: Basic Books, 2008

21. Ludwig DS, Kabat-Zinn J. Mindfulness in medicine. JAMA 2008; 300: 1350-2.

22. Launer B. Narrative-based primary care, a practical guide. Abingdon: Radcliffe Medical Press, 2002

23. Meland E. Informert samtykke ved mammografiscreening. Tidsskr Nor Legeforen 2009; 129: 2019-20.

24. Meland E. Autoritær medisin før og nå. Tidsskr Nor Lægeforen 2007; 127: 2704

Mottatt 31.1. 2012, første revisjon innsendt 27.3. 2012, godkjent 29.3. 2012. Medisinsk redaktør Are Brean. 